\title{
Probing the validity of the spinel inversion model: A combined SPXRD, PDF, EXAFS and NMR study of $\mathrm{ZnAl}_{2} \mathrm{O}_{4}$
}

Sanna Sommer, ${ }^{\mathrm{a}}$ Espen Drath Bøjesen, ${ }^{\mathrm{b}}$ Nina Lock, ${ }^{\mathrm{c}}$ Hidetaka Kasai, ${ }^{\mathrm{d}}$ Jørgen Skibsted, ${ }^{\mathrm{e}}$ Eiji Nishibori, ${ }^{\mathrm{d}}$ Bo Brummerstedt Iversen ${ }^{\mathrm{a} *}$

\begin{abstract}
Spinels are of essential interest in the solid-state sciences with numerous important materials adopting this crystal structure. One defining feature of spinel compounds is their ability to accommodate a high degree of tailorable point defects, and this significantly influences their physical properties. Standard defect models of spinels often only consider metal atom inversion between octahedral and tetrahedral sites, thereby neglecting other defects such as interstitial atoms. In addition, most studies rely on a single structural characterization technique, and this may bias the result and give uncertainty about the correct crystal structure. Here we explore the virtues of multi-technique investigations to limit method and model bias. We have used Pair Distribution Function analysis, Rietveld refinement and Maximum Entropy Method analysis of Powder X-ray Diffraction data, Zn edge Extended X-ray Absorption Fine Structure, and solid-state ${ }^{27}$ Al Nuclear Magnetic Resonance to study the structural defects in $\mathrm{ZnAl}_{2} \mathrm{O}_{4}$ spinel samples prepared by either microwave hydrothermal synthesis, supercritical flow synthesis, or spark plasma sintering. In addition, the samples were subjected to thermal post treatments. The study demonstrates that
\end{abstract}


numerous synthesis dependent defects are present and that the different synthesis pathways allow for defect tailoring within the $\mathrm{ZnAl}_{2} \mathrm{O}_{4}$ structure. This suggests a pathway forward for optimization of the physical properties of spinel materials.

\section{INTRODUCTION}

The famous defect free spinel structure encompasses compounds with the general chemical formula $\mathrm{AB}_{2} \mathrm{O}_{4}$, and the structure can be assigned to the cubic $\mathrm{Fd} \overline{3} \mathrm{~m}$ space group. The oxygen atoms arrange in a cubic close packing (Figure 1), where half of the 32 octahedral sites are occupied (Figure 1c, orange spheres) at the $16 d$ Wyckoff site, while the vacant sites are at $16 c$. Eight of the 64 tetrahedral sites are occupied at the $8 a$ Wyckoff site, while the vacant sites are at the $8 b$ and $48 f$ sites (Figure 1C, green, blue and yellow spheres, respectively). In the direct spinel structure, the divalent cations are positioned on the $8 a$ tetrahedral sites $\left(\mathrm{A}^{2+}\right)$ and the trivalent cations are on the $16 d$ octahedral sites $\left(\mathrm{B}^{3+}\right)$. The most common defect is inversion of the cations, described by the inversion factor $\mathrm{i}$ as $\left(\mathrm{A}_{1-\mathrm{i}} \mathrm{B}_{\mathrm{i}}\right)_{8 a}\left(\mathrm{~A}_{\mathrm{i}} \mathrm{B}_{2-\mathrm{i}}\right)_{66} \mathrm{O}_{4}$, where $\mathrm{i}$ spans from zero to one. Several factors influence $i$, such as the cation charge and size, the degree of covalence ${ }^{1,2}$ and crystal field stabilization effects. ${ }^{3,4}$ Minimization of the crystal field stabilization energy of the A and B ions in either a tetrahedral or octahedral environment is a common driving force behind potential inversion. For $\mathrm{ZnAl}_{2} \mathrm{O} 4, \mathrm{Zn}^{2+}$ has the electron configuration $[\mathrm{Ar}] \mathrm{d}^{10}$ while $\mathrm{Al}^{3+}$ is $[\mathrm{Ne}]$, i.e., $\mathrm{Zn}^{2+}$ and $\mathrm{Al}^{3+}$ ions have full and empty $d$ orbitals, respectively. Thus, the compound holds the potential to span from direct to fully inverted spinel without any changes in crystal field stabilization energy. Previously reported degrees of inversion for $\mathrm{ZnAl}_{2} \mathrm{O}_{4}$ are between $\mathrm{i}=0$ $0.33 .^{5-9}$ The Shannon and Prewitt ionic radii are $0.74 \AA$ and $0.53 \AA$ for tetrahedral $\mathrm{Zn}^{2+}$ and $\mathrm{Al}^{3+}$, 
respectively. ${ }^{10}$ The larger atomic radius of $\mathrm{Zn}$ compared to $\mathrm{Al}$, can therefore not explain the preference of $\mathrm{Zn}$ towards the smaller tetrahedral site.

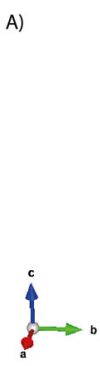

C)

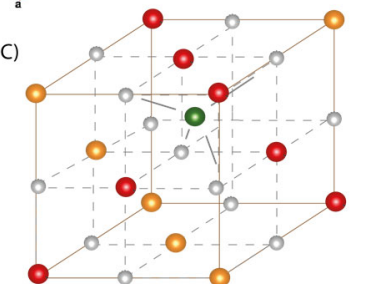

B)

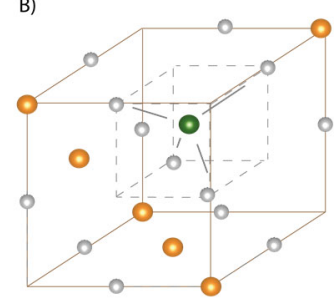

D)

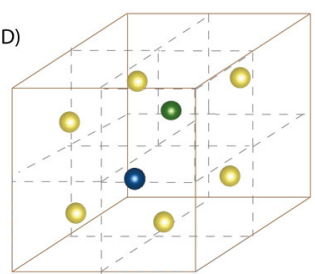

Figure 1. A) Crystal structure of $\mathrm{ZnAl}_{2} \mathrm{O}_{4} \cdot{ }^{11}$ The grey spheres represent oxygen in a cubic close packed lattice. Orange spheres represent the octahedral spinel $16 d$ site while green spheres represent the tetrahedral $8 a$ site. A black line indicates the unit cell. B) Zoom of one octant of the unit cell indicated by a brown box in A. C) Spinel unit cell with the potential interstitial octahedral cation site $16 c$ represented by red spheres. D) The tetrahedral sites are illustrated by dividing the brown box into eight smaller cubes. The tetrahedral sites are represented by green ( $8 a$ spinel site), blue (potential interstitial $8 b$ site) and yellow spheres (potential interstitial $48 f$ site).

The cation inversion model introduced in $1932^{12}$ is commonly assumed to be the only type of disorder in the spinel structure, and it is still widely applied. ${ }^{13,14}$ Theoretically, the energy of formation for other defects such as interstitials and vacancies is too high to be relevant compared with inversion and as a result they are typically neglected. ${ }^{15,16}$ The theoretical study of archetypical spinel $\mathrm{MgAl}_{2} \mathrm{O}_{4}$ by Ball et al. suggested that the formation energy of interstitials or vacancies is lowered when either is in the vicinity of another point defect of opposite charge. ${ }^{16}$ In agreement, 
theoretical DFT calculations by Dixit et al. show that under Zn rich conditions, oxygen vacancies are more likely to form. ${ }^{15}$ Experimentally, other point defects such as anion and cation interstitials or vacancies have been reported to exist in various spinel structures, ${ }^{16-18}$ but in the case of the $\mathrm{ZnAl}_{2} \mathrm{O}_{4}$ structure the available studies on alternative point defects are inconclusive. Cornu et al. observed residual electron density at the $16 c$ Wyckoff site $(0,0,0)$ in the difference Fourier map, which was ascribed to $\mathrm{Zn}$ interstitials, the study was based on conventional in-house Powder Xray Diffraction (PXRD) data. ${ }^{7}$ Recent theoretical and experimental studies have suggested that $\mathrm{Zn}$ and $\mathrm{O}$ vacancies also contribute significantly to the disorder. ${ }^{19-21}$

The degree of inversion in spinel structures affects the physical properties such as magnetic moment, charge carrier concentration and photoluminescence. ${ }^{15,22-26}$ In particular, $\mathrm{ZnAl}_{2} \mathrm{O}_{4}$ is a stable wide band gap semiconductor, where the photochemical properties can be controlled by inclusion of defects or dopants in the structure. ${ }^{21,24,27-33}$ Based on the specific structural defects in $\mathrm{ZnAl}_{2} \mathrm{O}_{4}$ both blue and near-white emission has been observed with a ms to $\mu$ s persistence. ${ }^{21}$ These properties and the high abundance of its constituent elements make $\mathrm{ZnAl}_{2} \mathrm{O}_{4}$ one of the cheapest transparent conducting oxides and it is used e.g. in solar cells. ${ }^{34}$ A detailed description of the point defects in specific $\mathrm{ZnAl}_{2} \mathrm{O}_{4}$ materials is interesting in itself, but such a description also serves as a benchmark for all spinel structures.

The most used method for quantitative determination of the inversion degree in spinel structures is Rietveld refinement of PXRD data. $\mathrm{ZnAl}_{2} \mathrm{O}_{4}$ is a good benchmark material to test the validity of this model, since the $\mathrm{X}$-ray scattering contrast between $\mathrm{Zn}$ and $\mathrm{Al}$ is more than a factor four ( $\infty \mathrm{f}^{2}, \mathrm{Z}_{\mathrm{Al}}=13$ and $\mathrm{Z}_{\mathrm{z}}=30$ ). However, the critical atomic occupancy parameters are (indirectly) correlated in Rietveld refinements, and it may be difficult to separate the individual contributions of cation inversion, oxygen occupancy (32e site) and potential interstitial defect sites 
since they all affect the relative intensity of the Bragg peaks (Figure S1-S8). Assuming inversion as the only defect, therefore, may provide incorrect estimates since alternative defects are wrongly absorbed into the inversion model (model bias). It should also be noted that for $\mathrm{ZnAl}_{2} \mathrm{O}_{4}$ the literature estimates of the inversion degree are generally based on in-house $\mathrm{CuK} \alpha_{1}$ radiation $\mathrm{PXRD}$ data. ${ }^{71}$ In the present study high-quality synchrotron Powder X-ray Diffraction (SPXRD) data are used to extract the subtle structural features.

The overall aim of this study is to obtain a better understanding of the different point defects generated during different $\mathrm{ZnAl}_{2} \mathrm{O}_{4}$ synthesis and post-treatments. We have previously studied the formation mechanism of $\mathrm{ZnAl}_{2} \mathrm{O}_{4}$ across various synthesis methods (microwave (M), supercritical flow (S) and spark plasma sintering (P)) and the effect of intermediate impurity phases. ${ }^{35,}{ }^{36}$ In these studies it was evident that a model where the only included point defect was inversion of the cations could not fully describe the SPXRD data. In particular, we observed relatively large refinement residuals for nanosized samples. Here we reexamine selected samples from the previous studies using a suite of different characterization methods: Pair Distribution Function (PDF) analysis, Rietveld refinement and maximum entropy methods (MEM) analysis of SPXRD data, Zn-edge Extended X-ray Absorption Fine Structure (EXAFS), and solid-state ${ }^{27}$ Al NMR. Subsequently, we link the results from the structural characterization to the absorption spectrum as determined by Diffuse Reflectance Ultraviolet Spectroscopy (DRS-UV-VIS) in an effort to establish a connection between the defect nature and physical properties.

\section{RESULTS AND DISCUSSION}


All samples, except sample M2, are phase-pure $\mathrm{ZnAl}_{2} \mathrm{O}_{4}$. The miniscule peak at $4.7^{\circ}$ in the SPXRD pattern of M2 indicates the presence of $\mathrm{AlOOH}$, albeit in an amount below the quantification limit with Rietveld refinement $\left(<<3 \mathrm{wt} \%^{36}\right)$. Table 1 provides an overview of the samples studied.

Table 1. Sample nomenclature, synthesis technique, and post treatment.

\begin{tabular}{c|c|c|c} 
Sample & Synthesis Technique & Post treatment & Procedure \\
\hline M2 & Microwave & None & Reference 35 \\
\hline M2w & Microwave & Washed in HCl & Experimental section \\
\hline S1 & Supercritical flow synthesis & None & Reference 35 \\
& Spark plasma sintering & None & Reference 28 \\
\hline P3 & Spark plasma sintering & $80^{\circ} \mathrm{C}$ for 5 days in air at & Experimental section \\
& P3a & ambient conditions & \\
\hline P3b & Spark plasma sintering & $80^{\circ} \mathrm{C}$ for 7 days in air at & Experimental section \\
& & ambient conditions & \\
& &
\end{tabular}

\section{SPXRD analysis on an "ideal powder" - The case of sample P3}

Due to the many correlated parameters during Rietveld refinement, the defect structure of a complex material is best determined by having a reference sample to which some parameters can be constrained. Ideally, high-quality reference data should be acquired from a stoichiometric single crystal with no inversion and limited Fourier error accumulation in high symmetry interstitial positions. ${ }^{37,38}$ We first compare the model obtained from high-quality SPXRD data on sample P3 with the results from single crystal X-ray diffraction analysis of O'Neill et al. ${ }^{11}$ This allows us to 
establish appropriate model constraints for the other samples. Sample P3 was synthesized using spark plasma sintering of stoichiometric amounts of mixed $\mathrm{ZnO}$ and $\gamma-\mathrm{Al}_{2} \mathrm{O}_{3}$ powders. The synthesis temperature of $1000{ }^{\circ} \mathrm{C}$ is below the threshold for evaporation from both precursor powders, and thus the stoichiometry should largely be maintained in the final product. The high ion mobility of $\mathrm{Zn},{ }^{39}$ may lead to gradients is the pressed pellet, but the ground up powder is expected to be stoichiometric.

The SPXRD pattern of sample $\mathrm{P} 3$ was modelled with $\mathrm{ZnAl}_{2} \mathrm{O}_{4}$ in the $\mathrm{Fd} \overline{3} \mathrm{~m}$ space group in accordance with single crystal refinements on $\mathrm{ZnAl}_{2} \mathrm{O}_{4}$ and other spinel structures. ${ }^{11,40}$ The oxygen atomic position was initially extracted from the study by $\mathrm{O}^{\prime} \mathrm{Neill}$ et al., which investigated both powder and single crystal data on in-house diffractometers. ${ }^{11}$ Their structural parameters derived from powder and single crystal data differed only within one standard deviation. The present P3 SPXRD data give the same atomic position for the oxygen atom, and therefore this is fixed in the refinements of SPXRD data on all the other samples.

In Rietveld refinements the Atomic Displacement Parameters (ADPs) commonly absorb model inadequacies. ${ }^{41}$ The refined ADPs for sample P3, using a model with no inversion, are fairly close to those of O'Neill et al., suggesting a limited degree of inversion (Table 2, Model 1 versus fixed ADP values in Model 3). Model 2 includes inversion of the cations and uses the single crystal ADPs provided by O'Neill et al. as an initial starting model. ${ }^{11}$ Upon refinement of the ADPs there is no change, and consequently they were fixed for all other refinements (Model 2 and fixed values in Model 3). The models indicate that sample P3 has a limited degree of inversion, with a refined value of $i=0.055(2)$. The profile fit of the Rietveld refinement for model 3 is shown in Figure $2 \mathrm{~A}$. The ADP value of oxygen at the $32 e$ position refines to a significantly higher value than for the single crystal data reported by O’Neill et al. (Model 1 versus fixed values of Model 3). This implies 
less scattering power on the site, which can be obtained by vacancies. Due to the relatively low scattering power of oxygen, it was not possible to extract reliable occupancies on this site, and full occupancy has been assumed in the following models.

Table 2. Rietveld refinement models. When interstitial sites are included in the model their occupancies are refined freely and thereby not obeying the 1:2 stoichiometric ratio of $\mathrm{Zn}: \mathrm{Al}$.

\begin{tabular}{|c|c|c|c|c|c|}
\hline Model & Sample & i (fraction) & $\begin{array}{c}\mathrm{ADP}, \mathrm{U}\left(\AA^{2}\right) \\
(8 a(\text { tet }) / 16 d(\mathrm{okt}) \\
/ 32 e(\mathrm{O}))\end{array}$ & Stoichiometry & $\begin{array}{l}\mathrm{R}_{\mathrm{wp}} / \\
\mathrm{R}_{\mathrm{b}} \\
(\%)\end{array}$ \\
\hline 1 & $\mathrm{P} 3$ & None & $\begin{array}{c}0.00292 / 0.00414 \\
/ 0.01194\end{array}$ & $(\mathrm{Zn})_{8 a}\left(\mathrm{Al}_{2}\right)_{16 d} \mathrm{O}_{4}$ & $\begin{array}{l}8.45 / \\
5.33\end{array}$ \\
\hline 2 & $\mathrm{P} 3$ & $0.055(2)$ & $\begin{array}{c}0.00407 / 0.00353 \\
/ 0.00470\end{array}$ & $\begin{array}{c}\left(\mathrm{Zn} 0.958 \mathrm{Al}_{0.042}\right)_{8 a}(\mathrm{Zn} 0.042 \\
\left.\mathrm{Al}_{1.958}\right)_{66 d} \mathrm{O}_{4}\end{array}$ & $\begin{array}{l}8.51 / \\
5.47\end{array}$ \\
\hline 3 & $\mathrm{P} 3$ & $0.055(2)$ & $\begin{array}{c}\text { Fixed } \\
(0.00407 / 0.0035 \\
3 / 0.00470)\end{array}$ & $\begin{array}{c}\left(\mathrm{Zn}_{0.949} \mathrm{Al}_{0.055}\right)_{8 a}\left(\mathrm{Zn}_{0.055}\right. \\
\left.\mathrm{Al}_{1.949}\right)_{16 d} \mathrm{O}_{4}\end{array}$ & $\begin{array}{l}8.51 / \\
5.48\end{array}$ \\
\hline 1 & $\mathrm{M} 2 \mathrm{w}$ & None & $\begin{array}{c}0.02092 /- \\
0.01051 /- \\
0.00334\end{array}$ & $(\mathrm{Zn})_{8 a}\left(\mathrm{Al}_{2}\right)_{16 d} \mathrm{O}_{4}$ & $\begin{array}{l}3.63 / \\
2.53\end{array}$ \\
\hline 3 & $\mathrm{M} 2 \mathrm{w}$ & $0.297(3)$ & $\begin{array}{c}\text { Fixed } \\
(0.00407 / 0.0035 \\
3 / 0.00470)\end{array}$ & $\begin{array}{c}\left(\mathrm{Zn}_{0.703} \mathrm{Al}_{0.297}\right)_{8 a}\left(\mathrm{Zn}_{0.297}\right. \\
\left.\mathrm{Al}_{1.703}\right)_{66 d} \mathrm{O}_{4}\end{array}$ & $\begin{array}{l}2.85 / \\
2.06\end{array}$ \\
\hline 4 & $\mathrm{M} 2 \mathrm{w}$ & $\begin{array}{c}\text { Occupancy: } \\
\mathrm{Zn}_{8 a}(0.70) / \\
\mathrm{Al}_{l 6 d}(0.42) / \\
\mathrm{Zn}_{l 6 d}(0.22) / \\
\mathrm{Al}_{8 a}(0.02)\end{array}$ & $\begin{array}{c}\text { Fixed } \\
(0.00407 / 0.0035 \\
3 / 0.00470)\end{array}$ & $\begin{array}{c}\left(\mathrm{Zn} 0.70 \mathrm{Al}_{0.02}\right)_{8 a}(\mathrm{Zn} 0.44 \\
\left.\mathrm{Al}_{0.84}\right)_{16 d} \mathrm{O}_{4}\end{array}$ & $\begin{array}{l}2.71 / \\
2.04\end{array}$ \\
\hline 5 & $\mathrm{M} 2 \mathrm{w}$ & $0.268(2)$ & $\begin{array}{c}\text { Fixed } \\
(0.00407 / 0.0035 \\
3 / 0.00470)\end{array}$ & $\begin{array}{c}\left(\mathrm{Zn}_{0.732} \mathrm{Al}_{0.268}\right)_{8 a}\left(\mathrm{Zn}_{0.268}\right. \\
\left.\mathrm{Al}_{1.732}\right)_{16 d}\left(\mathrm{Zn}_{0.082}\right)_{16 c} \mathrm{O}_{4}\end{array}$ & $\begin{array}{l}2.48 / \\
1.82\end{array}$ \\
\hline
\end{tabular}




\begin{tabular}{|c|c|c|c|c|c|}
\hline 6 & M2w & $\begin{array}{c}\mathrm{Al} \\
\text { stoichiometr } \\
\text { y constrain } \\
\text { maintained } \\
\text { while } \mathrm{Zn} \\
\text { occupancy is } \\
\text { refined } \\
\text { freely }\end{array}$ & $\begin{array}{c}\text { Fixed } \\
(0.00407 / 0.00353 / 0 \\
.00470)\end{array}$ & $\begin{array}{c}\left(\mathrm{Zn}_{0.825} \mathrm{Al}_{0.174}\right)_{8 a}\left(\mathrm{Zn}_{0.311}\right. \\
\left.\mathrm{Al}_{1.826}\right)_{16 d}\left(\mathrm{Zn}_{0.12}\right)_{16 c} \mathrm{O}_{4}\end{array}$ & $\begin{array}{c}2.54 / \\
1.91\end{array}$ \\
\hline 7 & $\mathrm{M} 2 \mathrm{w}$ & $0.254(2)$ & $\begin{array}{c}\text { Fixed } \\
(0.00407 / 0.0035 \\
3 / 0.00470)\end{array}$ & $\begin{array}{c}\left(\mathrm{Zn}_{0.746} \mathrm{Al}_{0.254}\right)_{8 a}\left(\mathrm{Zn}_{0.254}\right. \\
\left.\mathrm{Al}_{1.746}\right)_{16 d}\left(\mathrm{Zn}_{0.10}\right)_{16 c}\left(\mathrm{Zn}_{0.00}\right)_{48 \mathrm{f}} \mathrm{O}_{4}\end{array}$ & $\begin{array}{r}2.40 / \\
1.78\end{array}$ \\
\hline 8 & M2w & $\begin{array}{l}{ }^{27} \mathrm{Al} \mathrm{NMR} \\
\text { constrain of } \\
\mathrm{i}=0.102\end{array}$ & $\begin{array}{c}\text { Fixed } \\
(0.00407 / 0.0035 \\
3 / 0.00470)\end{array}$ & $\begin{array}{c}\left(\mathrm{Zn}_{0.898} \mathrm{Al}_{0.102}\right)_{8 a}\left(\mathrm{Zn}_{0.102}\right. \\
\left.\mathrm{Al}_{1.898}\right)_{16 d} \mathrm{O}_{4}\end{array}$ & $\begin{array}{l}3.64 / \\
2.19\end{array}$ \\
\hline 9 & $\mathrm{M} 2 \mathrm{w}$ & $\begin{array}{l}{ }^{27} \mathrm{Al} \text { NMR } \\
\text { constrain of } \\
\mathrm{i}=0.102\end{array}$ & $\begin{array}{c}\text { Fixed } \\
(0.00407 / 0.0035 \\
3 / 0.00470)\end{array}$ & $\begin{array}{c}\left(\mathrm{Zn}_{0.898} \mathrm{Al}_{0.102}\right)_{8 a}\left(\mathrm{Zn}_{0.102}\right. \\
\left.\mathrm{Al}_{1.898}\right)_{16 d}\left(\mathrm{Zn}_{0.092}\right)_{16 c} \mathrm{O}_{4}\end{array}$ & $\begin{array}{l}3.34 / \\
2.14\end{array}$ \\
\hline 10 & M2w & $\begin{array}{l}{ }^{27} \mathrm{Al} \text { NMR } \\
\text { constrain of } \\
\mathrm{i}=0.102\end{array}$ & $\begin{array}{c}\text { Fixed } \\
(0.00407 / 0.0035 \\
3 / 0.00470)\end{array}$ & $\begin{array}{c}\left(\mathrm{Zn} 0.898 \mathrm{Al}_{0.102}\right)_{8 a}\left(\mathrm{Zn}_{0.102}\right. \\
\left.\mathrm{Al}_{1.898}\right)_{16 d}\left(\mathrm{Zn}_{0.05}\right)_{48 f} \\
\left(\mathrm{Zn}_{0.076}\right)_{16 c} \mathrm{O}_{4}\end{array}$ & $\begin{array}{l}3.31 / \\
2.14\end{array}$ \\
\hline 11 & $\mathrm{M} 2 \mathrm{w}$ & $\begin{array}{c}\mathrm{Al} \\
\text { constrained } \\
\text { to }{ }^{27} \mathrm{Al} \text { NMR } \\
\mathrm{i}=0.102 \\
\text { with refined } \\
\mathrm{Zn} \\
\text { occupancy }\end{array}$ & $\begin{array}{c}\text { Fixed } \\
(0.00407 / 0.0035 \\
3 / 0.00470)\end{array}$ & $\begin{array}{c}\left(\mathrm{Zn} 0.890 \mathrm{Al}_{0.102}\right)_{8 a}(\mathrm{Zn} 0.319 \\
\left.\mathrm{Al}_{1.898}\right)_{16 d}(\mathrm{Zn} 0.006) 48 f \\
(\mathrm{Zn} 0.159) 16 c \mathrm{O}_{4}\end{array}$ & $\begin{array}{c}2.48 / \\
1.89\end{array}$ \\
\hline 12 & M2w & $\begin{array}{c}\mathrm{Al} \\
\text { constrained } \\
\text { to }{ }^{27} \mathrm{Al} \mathrm{NMR} \\
\text { ratio of } \\
\frac{A l_{\text {tet }}}{A l_{\text {oct }}}=0.054\end{array}$ & $\begin{array}{c}\text { Fixed } \\
(0.00407 / 0.0035 \\
3 / 0.00470)\end{array}$ & $\begin{array}{l}\left(\mathrm{Zn}_{0.920} \mathrm{Al}_{0.00}\right)_{8 a}\left(\mathrm{Zn}_{1.01}\right. \\
\left.\mathrm{Al}_{0.02}\right)_{16 d}\left(\mathrm{Zn}_{0.162}\right)_{16 c} \mathrm{O}_{4}\end{array}$ & $\begin{array}{r}2.46 / \\
1.87\end{array}$ \\
\hline
\end{tabular}




\begin{tabular}{|c|c|c|c|c|}
\hline & $\begin{array}{c}\text { With refined } \\
\text { Zn }\end{array}$ & & & \\
occupancy & & & & \\
\hline
\end{tabular}

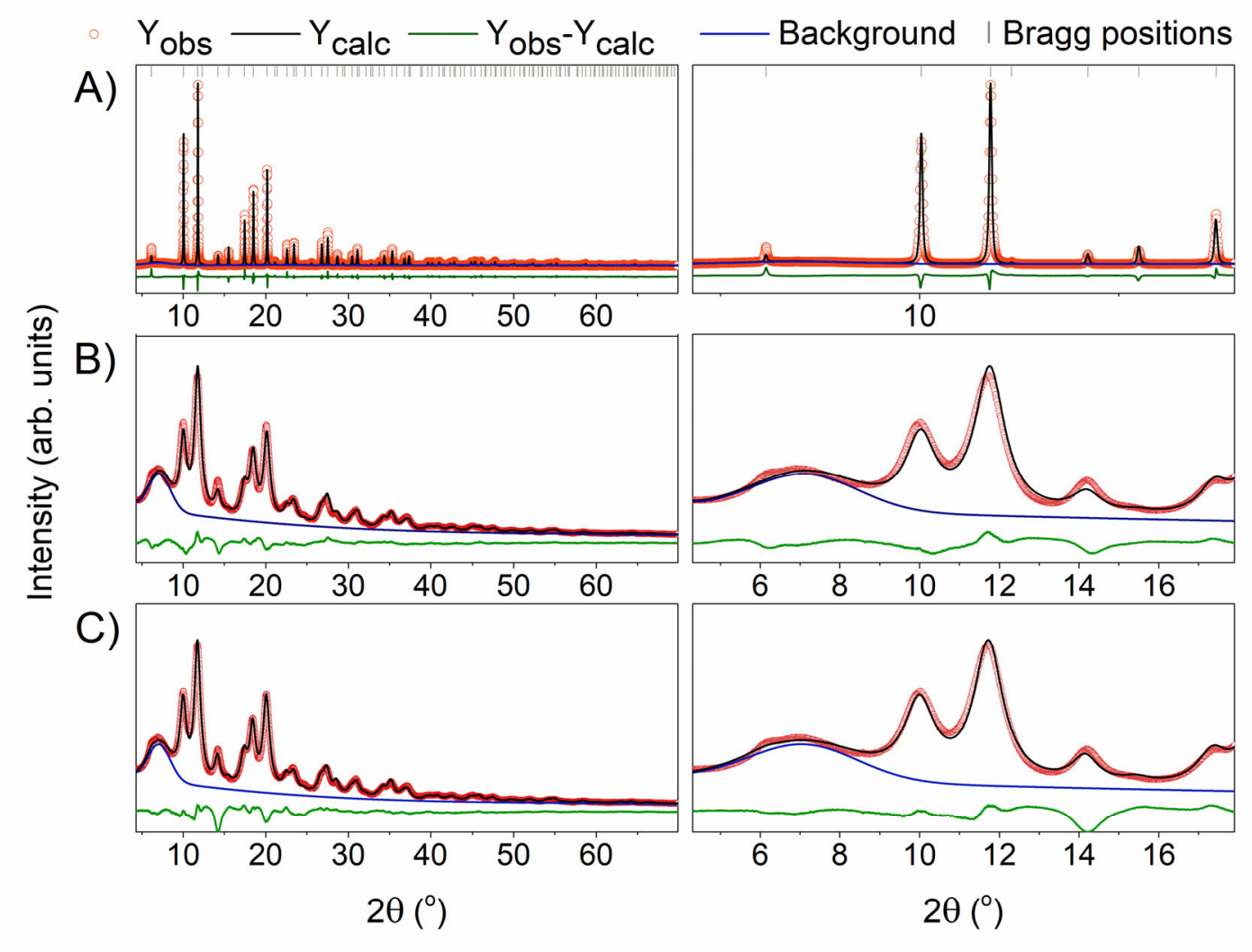

Figure 2. Rietveld refinement of synchrotron SPXRD data: A) sample P3 with model 3, B) sample M2w with model 3, C) sample M2w with model 11.

Exploring defects in the $\mathrm{ZnAl}_{2} \mathrm{O}_{4}$ structure - The case of sample $\mathrm{M} 2 \mathrm{w}$ 
Next we turn to sample M2w obtained from microwave hydrothermal synthesis. This is the sample with the largest amount of disorder. Modelling the SPXRD data assuming no inversion results in a high residual (Table 2, Model 1). The refined negative ADP values for $\mathrm{O}$ on the $32 e$ site and $\mathrm{Al}$ on the $16 d$ site are physically unreasonable. ${ }^{42}$ For the $16 d$ site, the model suggests that more scattering power is present, and this can be obtained by substituting $\mathrm{Zn}$ for Al. The high ADP values for the $8 a \mathrm{Zn}$ site suggest less scattering power. This can be obtained either by inversion, i.e. Al replacing $\mathrm{Zn}$, or alternatively by $\mathrm{Zn}$ vacancies. Overall, the SPXRD data clearly support cation inversion in this sample.

Model 4 includes inversion of the cations with free occupancy refinement according to $\left(\mathrm{Zn}_{\mathrm{x}}\right.$ $\left.\mathrm{Al}_{\mathrm{y}}\right)_{8 a}\left(\mathrm{Zn}_{\mathrm{v}} \mathrm{Al}_{\mathrm{w}}\right)_{16 d} \mathrm{O}_{4}$. This model provides an unreasonably low occupancy on both cation sites. If both sites are constrained to full occupancy according to $\left(\mathrm{Zn}_{1-\mathrm{i}} \mathrm{Al} \mathrm{l}_{\mathrm{i}}\right)_{8 a}\left(\mathrm{Zn}_{\mathrm{i}} \mathrm{Al}_{2-\mathrm{i}}\right)_{66} \mathrm{O}_{4}$ then the residual factor $\mathrm{R}_{\mathrm{B}}$ increases (Table 2, Figure 2B) indicating that a model only with cation inversion is inadequate. This is further supported by visual inspection, where the residuals are more pronounced at some peaks than other (Figure 2B).

The residual in the Rietveld refinement may partly be explained by additional point defects in the structure. Missing atoms in the structural refinement of Bragg diffraction data are typically located from difference Fourier synthesis. However, this standard crystallographic approach suffers from termination ripples since unmeasured data are given zero value in the Fourier summation. The MEM approach limits termination ripples, and it has been used widely in crystallography especially in analysis of very accurate data to obtain aspherical electron density distributions. ${ }^{43}$ Here we attempt to locate potential positions of interstitial atoms by MEM analysis of the SPXRD data. ${ }^{44-46}$ As shown in Figure 3, the MEM electron density is slightly dependent on the model applied in the Rietveld refinement to extract structure factors, in this case Model 1 and 
8. However, across all models the two potential sites of interstitial cations are the octahedral $16 \mathrm{c}$ site $(0,0,0)$ and a minuscule electron density at the tetrahedral $48 f$ site $(\sim 0.3330 .1250 .125$, Figure $3 \mathrm{~A}+\mathrm{C}$ and $3 \mathrm{D}$, respectively). The $16 c$ site was previously suggested as an interstitial site by Cornu et al., ${ }^{7}$ while occupation of the $48 f$ site has been observed for the $\mathrm{Li}_{4} \mathrm{Ti}_{5} \mathrm{O}_{12}$ and $\mathrm{Fe}_{3} \mathrm{O}_{4}$ spinel structures. ${ }^{17,18}$

Calculating the valence of the cations and comparing them to the expected valence of $\mathrm{Al}^{3+}$ and $\mathrm{Zn}^{2+}$ the most likely cation occupying the sites can be determined. This is based on the known bond distance and tabulated bond valence parameters. ${ }^{47}$ The calculated valence of $\mathrm{Al}^{3+}$ is 1.65 and 1.88 at the $16 c$ and $48 f$ site, respectively, and therefore these sites are unlikely to be occupied by $\mathrm{Al}^{3+}$. On the other hand, the calculated valence of $\mathrm{Zn}^{2+}$ approaches the expected valence with 1.85 and 2.17 respectively. In order to balance local charge, oxygen vacancies might be present surrounding the cation interstitial, however, in that case the valence only decrease further making the $\mathrm{Al}^{3+}$ occupation even more unlikely. On this basis the interstitial sites are most likely occupied by Zn.

Refinement of the M2w SPXRD data according to $\left(\mathrm{Zn}_{1-\mathrm{i}} \mathrm{Al}_{\mathrm{i}}\right)_{8 a}\left(\mathrm{Zn}_{\mathrm{i}} \mathrm{Al}_{2-\mathrm{i}}\right)_{16 d}\left(\mathrm{Zn}_{\mathrm{x}}\right)_{16 c} \mathrm{O}_{4}$ gives $\mathrm{x}=0.082$ (Model 5). Additionally including the $48 f$ site refine to almost zero occupancy (Model 7). The slight improvement of statistical parameters when including occupancy refinement on the $48 f$ site (compare Model 7 and Model 5), and the minuscule electron density observed at the site (Figure 3D) suggest that a detailed description of the structure should include the $48 f$ site, however, in most cases it can be neglected due to the low occupancy on the site.

Based on Rietveld refinements, Model 5 appears to be the most reliable model, which includes occupation on the octahedral $16 c$ site. This is based on the low statistical parameters, the reasonable refined values and the electron density in the Fourier difference map. The obtained 
stoichiometry, however, result in a slight positive overall charge of 0.16 , which in the real structure should be compensated by cation vacancies. These are most likely attributed to $\mathrm{Zn}$, due to the stoichiometry of the solution, which is expected to be reflected in the crystal, combined with the presence of $\mathrm{Zn}$ interstitial. A model combining the parameters in Model 5 with an individual refinement of the occupancy on both spinel $\mathrm{Zn}$ sites give unphysical occupation on the $16 d$ site with more than full occupancy, while there is hardly no change in the refined occupancy on the $8 a$ site (Model 6).

A)

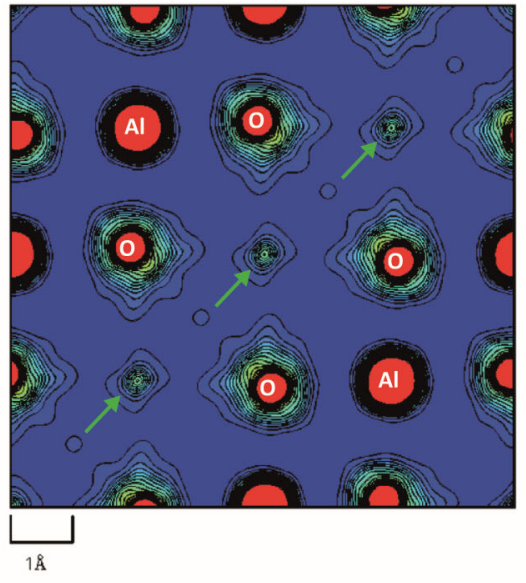

C)

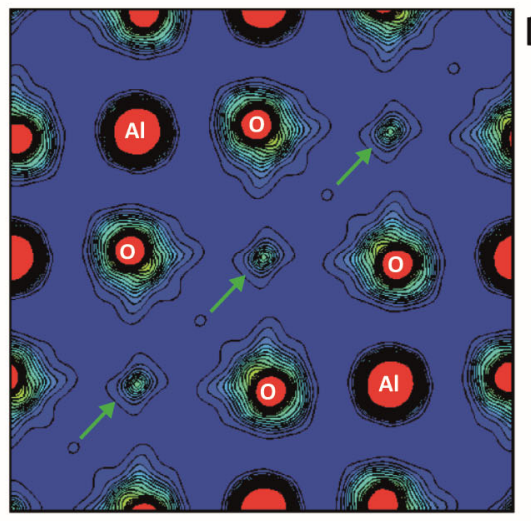

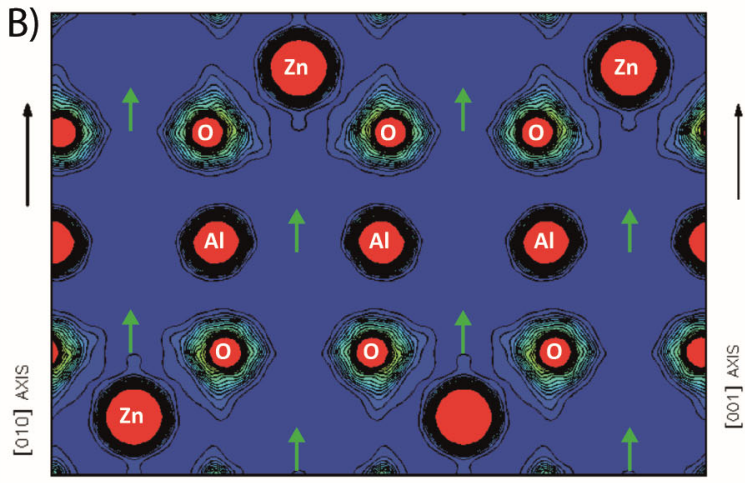

D)

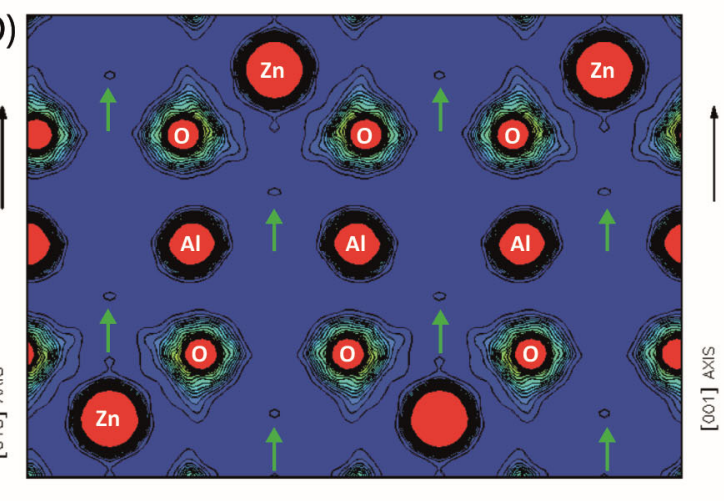

Figure 3. MEM electron density map of sample M2w using Model 1 (A and B) and Model 8 (C and D). The images to the left are for the [100] plane, where the $16 \mathrm{c}$ site is indicated by green 
arrows. The images to the right are for the $[-110]$ plane, where the $48 f$ site is indicated by green arrows. Contour lines are drawn from 0.0 to 2.0 in steps of $0.2 \mathrm{e}^{-3}$.

The following sections validate Model 5 by comparing the extracted degree of inversion to those predicted by other characterization techniques. ${ }^{27} \mathrm{Al} \mathrm{NMR}$ data can provide the fraction of tetrahedrally to octahedrally coordinated $\mathrm{Al}$ in the sample with no model bias. This is $5.1 \%$ tetrahedral and $94.9 \%$ octahedral coordination, for the M2w sample (Figure S9). Based on this fraction and the approximations given in the following, the degree of inversion for the $\mathrm{M} 2 \mathrm{w}$ sample is $i=0.102$. Here it is tentatively assumed that the spinel sites are fully occupied and that the amount of $\mathrm{Al}$ on the tetrahedral site is compensated by an equal amount of $\mathrm{Zn}$ on the octahedral site. Moreover, to account for the multiplicity, if each $\mathrm{Al}$ on the $16 d$ site has an occupancy of 0.949 the Al occupation on the $8 a$ sites must be 0.102 .

This degree of inversion obtained from NMR is almost three times lower than the value extracted from Rietveld analysis based on Model 5. The difference between the degree of inversion extracted from the two techniques is only increased if the interstitial $16 \mathrm{c}$ site is not included in the SPXRD model (Model 3). 


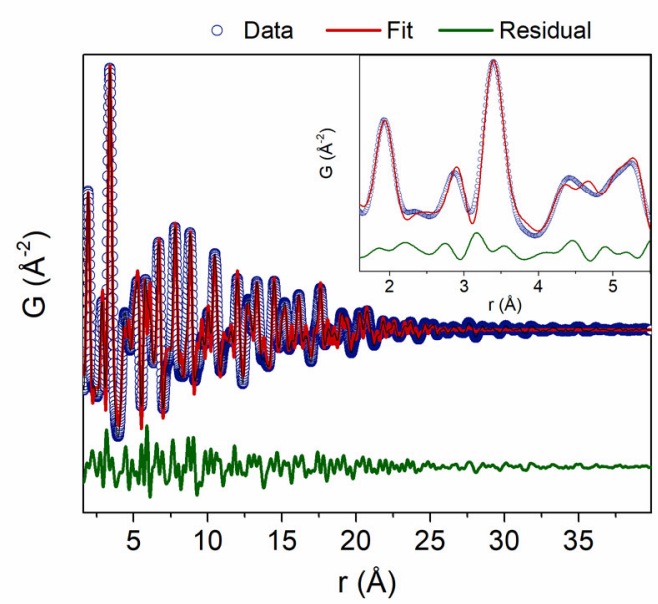

Figure 4. PDF model using the crystalline approach on the M2w dataset applying Model 5. The insert is a zoom of the first few interatomic distances.

The NMR result of $\mathrm{i}=0.102$ only holds if there is almost no amorphous material in the sample (since NMR does not distinguish between crystalline and amorphous fractions). Sample M2 and M2w are too small to deduce the crystallinity based on TEM images (Figure S11). (S)TEM analysis of sample S1 suggests that the particles are fully crystalline since clear lattice fringes are observed to the edge of the particles (Figure S12-S13). Even so the sample may contain amorphous material in addition to the individual particles. PDF analysis provides information about both the crystalline and amorphous parts of a sample. Application of model 5 to the PDF data yields $\mathrm{i}=$ $0.25(5)$, in good agreement with the Rietveld analysis giving $\mathrm{i}=0.268(2)$. The similar values indicate that the two techniques probe the same sample and thereby that the sample is relatively crystalline. Presence of amorphous material would especially manifest itself as residual intensity at low $\mathrm{r}$ in the PDF data, and this is not observed, Figure 4. In summary, it seems reasonable to assume that the majority of the M2w sample is crystalline, and therefore the ${ }^{27} \mathrm{Al}$ NMR value of 5.1\% tetrahedrally coordinated $\mathrm{Al}$ in $\mathrm{ZnAl}_{2} \mathrm{O}_{4}$ is assumed valid in the following. 
If the ${ }^{27} \mathrm{Al} \mathrm{NMR}$ inversion value is used to constrain the Rietveld model a worse fit is obtained (Model 8). Using $\mathrm{i}=0.102$ while refining the occupancy on the $16 \mathrm{c}$ interstitial site improves the fit, with a refined stoichiometry of $\left(\mathrm{Zn}_{0.898} \mathrm{Al}_{0.102}\right)_{8 a}\left(\mathrm{Zn}_{0.102} \mathrm{Al}_{1.898}\right)_{16 d}\left(\mathrm{Zn}_{0.092}\right)_{16 c} \mathrm{O}_{4}$, Model 9. Including also $\mathrm{Zn}$ on the $48 f$ interstitial site reduces the profile residual further, while the Bragg peaks are equally well described (Model 10). The resulting stoichiometry is ( $\mathrm{Zn} 0.898$ $\left.\mathrm{Al}_{0.102}\right)_{8 a}\left(\mathrm{Zn}_{0.102} \mathrm{Al}_{1.898}\right)_{16 d}(\mathrm{Zn} 0.05)_{48 f}\left(\mathrm{Zn}_{0.076}\right)_{16 c} \mathrm{O}_{4}$. In both cases, this corresponds to almost the same amount of interstitial defects as the amount of inversion of the cations. However, both models suffer from too high an overall charge, which like for Model 5 must be compensated by cation vacancies, likely $\mathrm{Zn}$. In this regard, it is worth stressing that the ${ }^{27} \mathrm{Al}$ NMR only provides information about the local $\mathrm{Al}$ environment. If Model 10 is combined with refinement of the occupancy of $\mathrm{Zn}$ on the $8 a$ and $16 d$ site a further improvement of the fit is obtained (Model 11). However, the refined values suggest more that full occupancy on the $16 d$ site.

Again, it is worth considering the initial approximations regarding ${ }^{27} \mathrm{Al} \mathrm{NMR}$. While the ratio between tetrahedrally and octahedrally coordinated $\mathrm{Al}$ is provided by this technique, full occupancy on the spinel sites is not required. Model 12 combines the parameters of Model 11 with refinement of the $\mathrm{Al}$ occupancy, while maintaining the ratio provided by ${ }^{27} \mathrm{Al} \mathrm{NMR}$. This result in an unphysical structure with only half occupancy on the $16 d$ site and almost no $\mathrm{Al}$ in the structure.

To summarize on SPXRD, the technique taken alone indicated that the most reliable model was Model 5 based on the residual electron density in the $16 \mathrm{c}$ and $48 f$ site and the low statistical parameters. However, the model predicted a slightly positive charge, which could be compensated by cation vacancies, but this was not possible to model reliably. The alternative to this model is the simple inversion Model 3 which has a zero overall charge. However, both of these models predict vastly higher inversion than the ${ }^{27} \mathrm{Al}$ NMR, which suggest that (S)PXRD alone is not able 
to describe the defect structure. This is despite the X-ray scattering power difference between $\mathrm{Zn}$ and $\mathrm{Al}$ is large, and the use of synchrotron data of very high quality.

When the ${ }^{27} \mathrm{Al}$ NMR constraint is introduced, Model 10 and 11 are the most reliable models, with lower statistical parameters. However, despite the complexity of these models the overall charge become positive, which indicates that the models are still not fully adequate.

Two other characterization techniques commonly used to determine the degree of inversion are PDF and EXAFS. For both techniques information can be obtained both trough modelling as well as qualitatively considering e.g. the peak positions. The structural models, which were investigated using Rietveld refinements have also been examined with PDF analysis. The PDF models show the same trends and are, therefore, not able to predict the degree of inversion by themselves (Figure S14-S16, Table S2). Using the ${ }^{27} \mathrm{Al}$ NMR constraint gives support to Model 10 with additional un-modelled cation vacancies, while both Model 11 and 12 become unphysical. Considering the qualitative information in the PDF, the first peak contain the bond distance of $\mathrm{Zn} / \mathrm{Al}-\mathrm{O}$ (Figure 4 insert). The spinel $8 a$ and $16 d$ sites have a bond distance of $1.9 \AA$ corresponding to the maxima of the peak, while the interstitial sites are at the shoulders of the peak. The $16 c$ has a bond distance of $2.1 \AA$ while the $48 f$ is split with two distances at $1.68 \AA$ and two at $1.93 \AA$. The fact that the maximum of the first peak coincide with the spinel bond distance of $1.9 \AA$ supports that the main cation occupancy is located at the spinel sites.

$\mathrm{Zn}$-EXAFS probes the local environment around the $\mathrm{Zn}$ atoms. Due to the low number of peaks in real space, the complex models used for SPXRD and PDF analysis would overparametrize the data. Instead, the simple inversion model has been applied (Model 3), which yields $i=0.32(17)$, though with significant residuals beyond the first peak (Figure S17). This suggests that the combination of scattering paths originating from the $8 a$ and $16 d$ sites is not sufficient to 
describe the local environment of $\mathrm{Zn}$ in the sample. Since the nearest neighbor bond distances are similar between the four sites, but the following distances are very different, this leans support to the presence of interstitials.

\section{How can defects be induced in $\mathrm{ZnAl}_{2} \mathrm{O}_{4}$ : The case of $\mathrm{M} 2$ versus $\mathrm{M} 2 \mathrm{w}$}

Theoretical studies performed by Lahmer and Dixit et al. suggest that at ideal conditions only cation inversion is relevant, but non-stoichiometric conditions facilitate formation of other defects. $^{15,20}$ According to literature, a certain $\mathrm{pH}$ range facilitates formation of phase-pure $\mathrm{ZnAl}_{2} \mathrm{O}_{4} \cdot{ }^{7,36,48}$ Sample M2 is synthesized in this range with $\mathrm{Zn}: \mathrm{Al}: \mathrm{OH}=1: 2: 7$, whereas sample $\mathrm{M} 2 \mathrm{w}$ is synthesized using an 1:2:8 ratio (the other synthesis parameters are identical). M2w contained $\mathrm{ZnO}$ impurities (removed with $\mathrm{HCl}$ ), i.e. it is formed under non-stoichiometric conditions. MEM analysis of the M2 sample show residual electron density at the same sites as sample M2w (Figure S23). The ${ }^{27} \mathrm{Al}$ NMR results suggest that the M2w sample has almost double the degrees of inversion compared to M2 ( $\mathrm{i}=0.102$ and 0.054 respectively, Figure 5A). Additionally, the other characterization methods indicate that sample M2w has a significantly higher amount of point defects; Zn-EXAFS analysis suggesting four times more inversion (0.32 vs 0.067 ) while the ratio is 1:1.4 based on SPXRD and PDF analysis (Figure 5A). Thus, the M2w sample is clearly the most defect sample. The present data lends support to the theoretical calculations on the relative energies of defects under different synthesis conditions, and clearly the specific synthesis method strongly affects the concentration of the defects. 

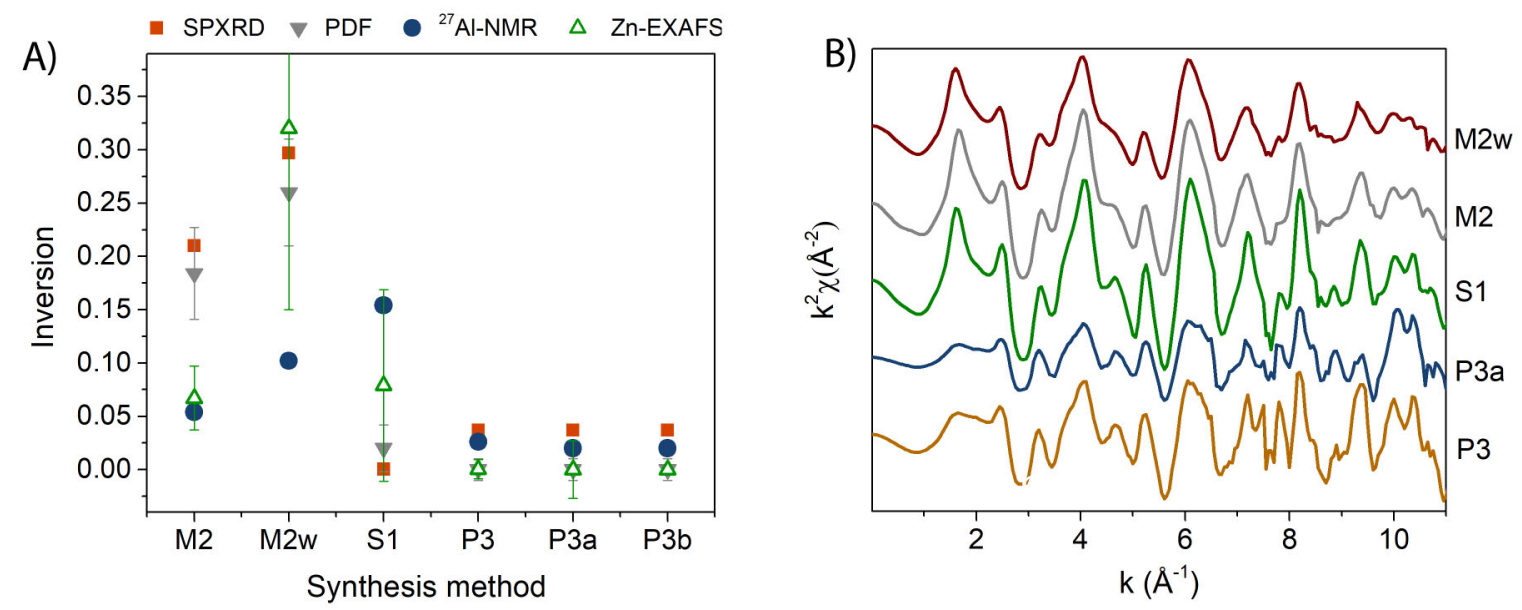

Figure 5. A) Degree of inversion for various samples based on SPXRD, PDF, ${ }^{27} \mathrm{Al}$ NMR and ZnEXAFS applying model 3, i.e. assuming that inversion is the only disorder present and full occupancy and stoichiometry is maintained. B) Raw Zn-EXAFS data for samples M2w, M2, S1, $\mathrm{P} 3 \mathrm{a}$ and $\mathrm{P} 3$. There are clear variations in the local $\mathrm{Zn}$ environment between the different $\mathrm{ZnAl}_{2} \mathrm{O}_{4}$ samples, and e.g. at 1-3 $\AA^{-1}$ the features are more pronounced for the highly defective microwave samples (M2w and M2) compared with the almost defect free spark plasma sintered samples, P3a and P3.

\section{The simple inversion model and knowledge gained across samples}

For the M2w sample the simple inversion Model 3, which is commonly used in literature, was not accurately describing the defects. To validate if this is a general trend, Model 3 was applied in all characterization techniques of samples synthesized in various ways (Figure 5A).

For sample $\mathrm{P} 3, \mathrm{P} 3 \mathrm{a}$ and $\mathrm{P} 3 \mathrm{~b}$, there is a decent agreement between the predicted degrees of inversion for the various structural characterization techniques, and they all suggest a minimal amount of inversion. For the other more defective samples the inaccuracy of the simple inversion model was manifested in a similar fashion as for the M2w sample, e.g. generally, the techniques 
predict different degrees of inversion indicating model bias. Thus, the simple inversion model is not able to reliably describe defective samples. The difference in defects between the samples is qualitatively observed as systematic variations in the raw EXAFS signal. As an example, it appears that samples synthesized by spark plasma sintering have similar EXAFS features, which are distinctly different from the other samples (Figure 5B). It is noteworthy that the extracted degrees of inversion by different techniques would not by themselves be considered unreasonable, ${ }^{5-8}$ and it is only due to the multi-technique investigation that we are able to discriminate. As an example the inversion degrees for the $\mathrm{M} 2 \mathrm{w}$ sample spans from 0.102 to 0.32 .

The study of spinel $\mathrm{MgAl}_{2} \mathrm{O}_{4}$ by Ball et al. based on theoretical calculations suggests, that the formation energy of interstitials or vacancies is lowered by being near another point defect of opposite charge. ${ }^{16}$ A high degree of cations inversion will, therefore, lower the barrier for formation of adjacent point defects. This theory is supported by our study for the M2 and M2w

samples, where a high degree of inversion predicted by ${ }^{27} \mathrm{Al}$ NMR is accompanied by presumably larger amounts of additional point defects observed as higher values for the degree of inversion predicted by PDF, SPXRD and Zn-EXAFS (Figure 5A). The contrary is observed for sample S1. Pathak et al. have based on multiple characterization techniques suggested that point defects in their $\mathrm{ZnAl}_{2} \mathrm{O}_{4}$ sample occur as clusters of, e.g. $2 \mathrm{VZn}^{-}-\mathrm{Vo}$, rather than single units. ${ }^{21}$

\section{The influence of heat treatments}

Previous studies have found that the inversion degree depends significantly on the thermal history of the sample, which in general decrease with increasing temperature. ${ }^{7,21,49-51}$ The fact that the degree of inversion is dependent on thermal history has been reported for other spinel systems 
such as $\mathrm{ZnFe}_{2} \mathrm{O}_{4}$ and $\mathrm{MgAl}_{2} \mathrm{O} .{ }^{52,53}$ However, in most of these studies additional defects such as interstitials and vacancies are not taken into account.

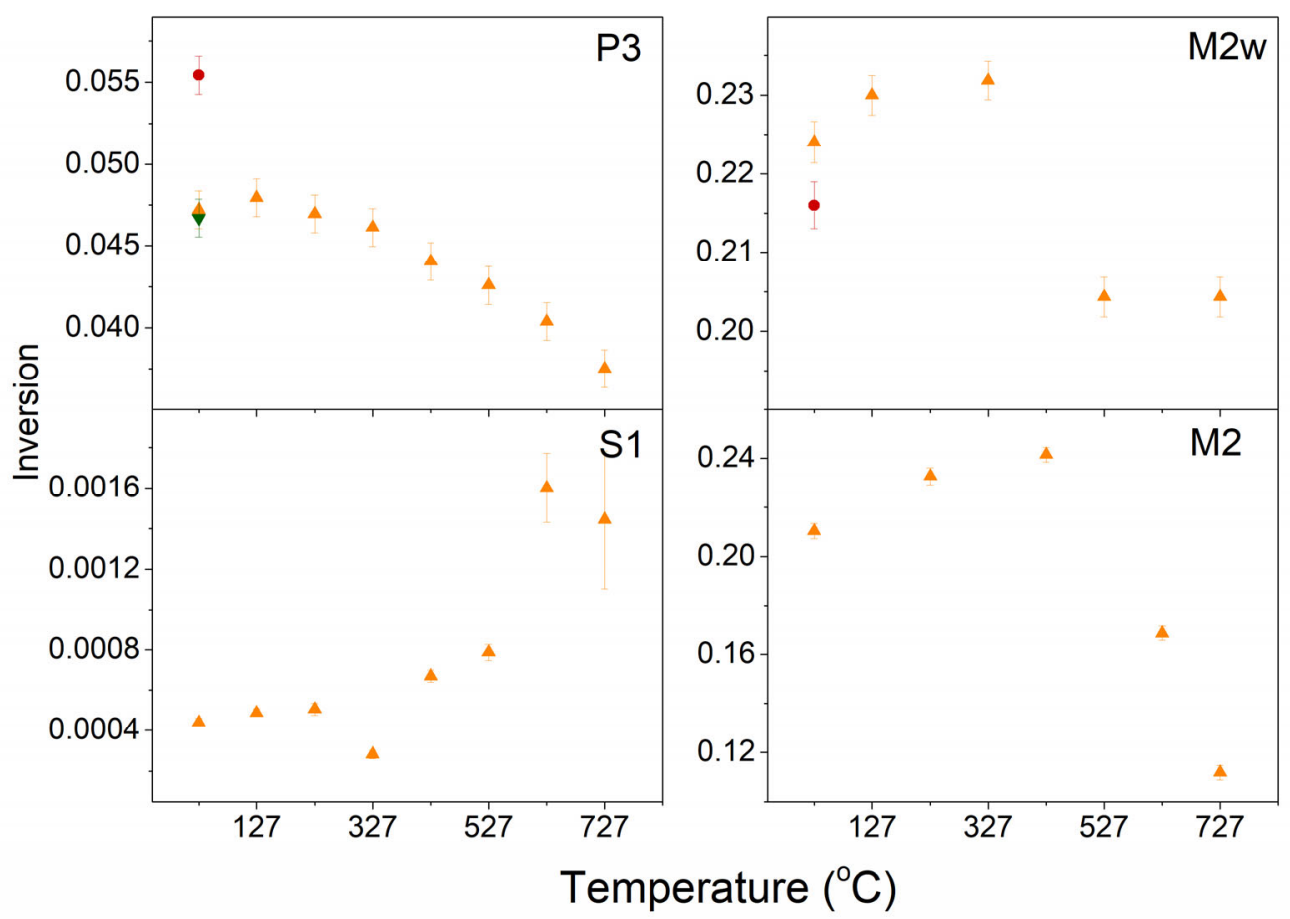

Figure 6. Estimated degree of inversion from Rietveld refinements of in situ SPXRD data of sample P3, M2w, S1 and M2 heated treatment in air. The green triangle is the degree of inversion at $27^{\circ} \mathrm{C}$ after the sample has been heated to $727^{\circ} \mathrm{C}$, while the red circle is the degree of inversion extracted from data acquired in the low temperature setup. There is a discrepancy in the predicted degree of inversion between the low and high temperature setups.

In Figure 6 the inversion degree is shown for samples P3, S1, M2 and M2w as a function of temperature. The values were obtained from Rietveld refinement of Model 3 against SPXRD data measured on the powders during heating in air. Sample S1 has an almost zero degree of inversion, 
but it increases slightly with increasing temperature - it is likely insignificant. The P3 sample has a gradual decrease in the inversion degree from 0.055 at $27^{\circ} \mathrm{C}$ to 0.038 at $727^{\circ} \mathrm{C}$, which also might be insignificant. The more defect samples, M2 and M2w show fairly constant inversion up to 427 ${ }^{\circ} \mathrm{C}$, followed by a drop. The similar behavior with temperature suggests that the main cation diffusion mechanism is similar in the two latter defective samples, and that it has an activation barrier, which is overcome at temperatures between $427^{\circ} \mathrm{C}$ and $627^{\circ} \mathrm{C}$.

\section{The absorption spectrum and its relation to the defects}

$\mathrm{ZnAl}_{2} \mathrm{O}_{4}$ can be used as a phosphor, and trends between the defects and the absorption spectra can be established based on our portfolio of samples. ${ }^{35,36}$ This can be used to either avoid the defects if the aim is doping the $\mathrm{ZnAl}_{2} \mathrm{O}_{4}$ structure, or increase the understanding on how the emission from pure $\mathrm{ZnAl}_{2} \mathrm{O}_{4}$ can be tuned.
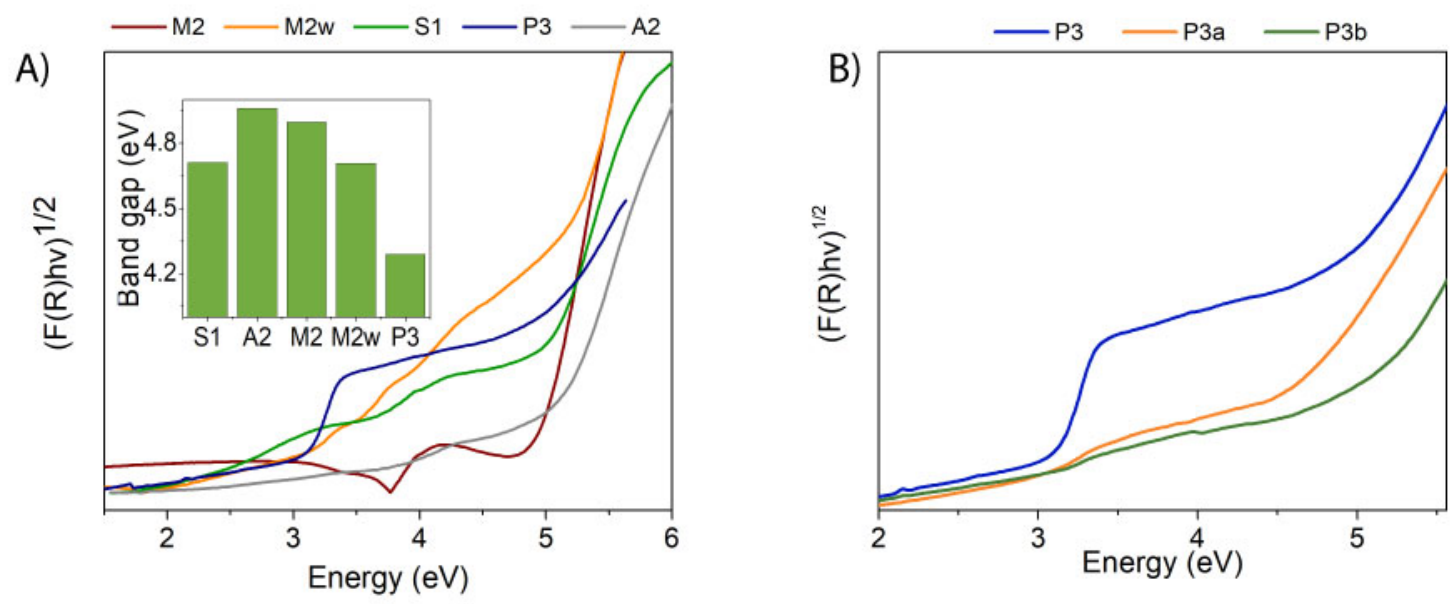

Figure 7. A) Kubelka-Munk function of sample M2, M2w, S1 P3 and A2. Sample conditions for sample A2 can be found in reference. ${ }^{36}$ The insert show the extracted band gap of the samples. B) Kubelka-Munk function of $\mathrm{P} 3$ heated for 5 days (P3a) and 7 days (P3b) at $80{ }^{\circ} \mathrm{C}$. 
Figure 7A shows the absorption spectra of the samples, where most of them has a complex curve, suggesting one or several defect states in the band gap. This corresponds well with the structural analysis where e.g. sample M2w contain both inversion and $\mathrm{Zn}$ interstitials at the $16 \mathrm{c}$ and $48 f$ site. The sample probably also contains cation vacancies. When considering the other samples we also see agreement between the structural analysis and the spectra. Sample M2 contain less defects than sample $\mathrm{M} 2 \mathrm{w}$ and correspondingly contain less absorption beyond what is expected from the main band gap. The M2 sample has a tiny amount of $\mathrm{AlOOH}$ present, which might attribute to the absorption spectrum. The S1 sample has absorption at other energies than the remaining samples. During the structural analysis of sample S1, the PDF and SPXRD techniques predicted a lower degree of inversion compared with the other techniques (Figure 5A). This is in contrast to the other hydrothermally synthesized samples, where PDF and SPXRD suggested a higher amount of inversion. Both of these observations suggest that S1, synthesized by supercritical flow synthesis has a different defect structure than the samples synthesized through microwave synthesis.

The absorption spectrum of sample P3 contains a shoulder at 3.0-3.5 eV, while it is absent in other samples e.g. in A2. ${ }^{36}$ To determine which defect state can be attributed to the absorption shoulder, the sample was exposed to heat treatment for 5 and 7 days at $80{ }^{\circ} \mathrm{C}$ ( $\mathrm{P} 3 \mathrm{a}, \mathrm{P} 3 \mathrm{~b}$, respectively). No significant changes was observed in the extracted degree of inversion or in the PDF and SPXRD patterns, (Figure 4A and S24), while the absorption at 3.0-3.5 eV decreased (Figure 7B). This indicates that the structural changes arise from an element with a low scattering power. Also, there was no change in neither the ${ }^{27} \mathrm{Al}$ NMR nor the Zn-EXAFS data suggesting that the disorder in P3 is most likely due to O interstitials or vacancies. Based on the large covalent 
radii of the $\mathrm{O}$ atom, interstitials are rarely formed. ${ }^{15}$ Several theoretical as well as experimental studies suggest that the oxygen vacancies are readily formed in the spinel structure and that they are temperature dependent. ${ }^{19-21,27,31,54}$ In summary, heating of the samples in an oxygen containing atmosphere most likely fills up oxygen vacancies and thereby causes the shoulder in the KubelkaMunk function to diminish. This rules out that absorption shoulders should automatically be assigned to the degree of inversion as has previously been suggested in literature. ${ }^{7,21}$

Sample P3 has a very limited degree of inversion (Figure 5A) and during calcination the oxygen vacancies are filled, therefore, the calcined product has no significant defect states in the absorption spectrum (Figure 7B). This makes sample P3b a promising candidate as a white host material. Likewise, sample A2 synthesized by autoclave synthesis over 17 days has no significant defect states in the absorption spectrum (Figure 7A). Sample A2 has a long synthesis time, but it can be performed in one-step and in a large batch.

During the in situ SPXRD calcination we observed a gradual decrease in the degree of inversion of sample P3 (Figure 6). On the other hand PDF and Zn-EXAFS suggested that already at room temperature the sample contained no inversion. From the absorption spectra it is clear that this sample has oxygen vacancies. The degree of inversion is $82 \%$ correlated with oxygen vacancies during Rietveld refinements and it seems likely that the decrease in the degree of inversion with increasing temperature is partly due to a decrease in oxygen vacancies. Other samples could have a different behavior, but the P3 sample can be used to exemplify that the trends in the degree of inversion versus the thermal treatment require more than one technique to be reliably determined.

The large difference in the absorption spectra and extracted band gaps suggest that the defect structure is highly dependent on the synthesis procedure and post treatment (Figure 7A). 
There is no single value for the band gap of $\mathrm{ZnAl}_{2} \mathrm{O}_{4}$, and the band gap properties can be tailored through the defect structure. Based on the samples presented in this paper we do not observe correlation between the band gap and the crystallite size or with the degree of inversion (Figure S27), as has been previously argued in literature..$^{21,55}$

It is difficult to establish trends between the different synthesis procedures as many parameters change, however in our previous spark plasma sintering study of $\mathrm{ZnAl}_{2} \mathrm{O}_{4}$, we observed that the band gap could be tailored by $1 \mathrm{eV}$ e.g. as a function of synthesis dwell time ( 0 to $25 \mathrm{~min}$ ), where sample P3 has a dwell time of 5 min. ${ }^{35}$ Pathak et al. established based on DFT calculations, that the band gap increase with the presence of oxygen vacancies. ${ }^{21}$ In the context of the spark plasma synthesized samples this corresponds to an increase in the amount of oxygen vacancies with increasing dwell time. This is further supported by the extracted unit cell parameters, which decrease with increasing dwell time, which can be explained by the absence of the large oxygen atoms.

\section{EXPERIMENTAL}

\section{Synthesis}

The pellets synthesized directly by spark plasma sintering were pressed according to Sommer et $a l .{ }^{35}$ A pellet synthesized in the same manner as $\mathrm{P} 3$ was crushed and heated in an oven for 5 days and 7 days at $80^{\circ} \mathrm{C}$. These samples are named $\mathrm{P} 3 \mathrm{a}$ and $\mathrm{P} 3 \mathrm{~b}$, respectively.

Samples M2 and S1 were synthesized by microwave synthesis (M) and supercritical flow synthesis (S), respectively, according to the work by Sommer et al. ${ }^{36}$ Sample M2w (w=wash) is synthesized with a $\mathrm{Zn}: \mathrm{Al}: \mathrm{OH}$ ratio that fosters formation of the impurity $\mathrm{ZnO}$ (1:2:8 versus 1:2:7 
for M2). All other parameters are identical to the M2 sample. Residual $\mathrm{ZnO}$ was removed for the M2w sample by washing the powder in a $2 \mathrm{M} \mathrm{HCl}$ solution.

\section{Synchrotron Powder X-ray Diffraction (SPXRD)}

The SPXRD data was collected at beamline BL44B2 at the SPring-8 synchrotron facility, Japan.

${ }^{56}$ The samples were packed in $0.3 \mathrm{~mm}$ capillaries (Hilgenberg $\mathrm{GmbH}$ ) and mounted on a standard goniometer head, where samples were rotated throughout the experiment to ensure a good powder averaging. Quartz capillaries were used for room temperature and higher temperature experiments, whereas glass capillaries were used at lower temperatures to obtain higher sample-to-background statistics. All SPXRD experiments were conducted at $\lambda=0.50054(6) \AA$ in Debye-Scherrer geometry using an image plate detector, while the data was refined using MAUD. ${ }^{57}$ The Instrumental Resolution Function was determined from a $\mathrm{CeO}_{2}$ standard, which was refined to obtain the exact wavelength and also to extract profile parameters describing the contributions from the instrument. The background was modelled using a combination of four polynomial functions and two background Gaussian functions describing the small angle scattering and scattering from the glass capillary. Size broadening was refined using two spherical harmonic functions to account for any non-isotropic particle morphologies. The morphology of the particles are previously analyzed and described in the work by Sommer et al. ${ }^{36}$

MEM analysis was performed against the structure factors with $\mathrm{d}>0.4 \AA$ resolution using the program ENIGMA. ${ }^{58}$ In the calculation, the unit cell was divided by $128 \times 128 \times 128$ pixels. The structural model used the single crystal ADP values and oxygen positions provided by O'Neill et $a l .{ }^{11}$ The direct spinel structure $(\mathrm{i}=0)$ was applied in the calculations (Model 1). Additionally a model was constructed assuming the ${ }^{27} \mathrm{Al} \mathrm{NMR}$ results as the degree of inversion (Model 7) 


\section{Pair Distribution Function (PDF)}

The total X-ray scattering data was collected at P02.1, DESY, Germany on a two-dimensional Perkin Elmer XRD1621 area detector and integrated using Fit2D. ${ }^{59}$ The intensity $I_{T}$ from a scattering experiment has several contributions, $I_{T}=I_{C}+I_{B G}+I_{I C}+I_{M S}$, where the coherent scattering $I_{C}$ contains the desired structural information. $I_{B G}$ is the background scattering, which is obtained by performing an identical experiments of an empty capillary. $I_{I C}$ and $I_{M S}$ are the intensity of the incoherent and multiple scattering, respectively, which are taken into account by the ad hoc method implemented in the PDFgetX3 software. ${ }^{60} I_{B G}$ can be subtracted from the $a d$ hoc corrected $I_{T}$ and thereby provide the signal from the sample.

The resulting PDFs were analyzed using PDFgui ${ }^{40} \mathrm{Two}_{\mathrm{ZnAl}} \mathrm{O}_{4}$ phases, each with spherical morphology, were used to model the known non-spherical particle morphology. The unit cell parameter and degree of inversion was refined, but the values were fixed to be identical for the two "phases". The atomic displacement parameters were fixed to the single crystal values provided by O’Neill et al. ${ }^{11}$ The instrumental damping parameter, Qdamp, was determined using a LaB $6660 \mathrm{~b}$ NIST standard at equal conditions.

\section{Transition Electron Microscopy (TEM)}

Bright field TEM images were recorded on a TALOS F200A with a TWIN lens system, X-FEG electron source and a Ceta 16M Camera. STEM images were collected using a high angle annular dark field detector on the same microscope. The microscope is equipped with a Super-X EDS detector and the EDS data collection was controlled using the Bruker Esprit software. The EDS spectra were plotted using Hyperspy. ${ }^{61}$ Samples were prepared by sonication of dried powders 
dispersed in $99 \%$ ethanol. Individual drops were placed on TEM grids (200 mesh copper grid with formvar/carbon support film) and dried in ambient atmosphere. The electron microscopy data are available in the supporting information.

\section{Extended X-ray Absorption Fine Structure (EXAFS)}

The Zn-EXAFS experiments were performed in transmission mode at beamline BL26B2, SPring8, Japan. ${ }^{62}$ The powders were packed in $0.3 \mathrm{~mm}$ glass capillaries and data was collected at -173 ${ }^{\circ} \mathrm{C}$ at the $\mathrm{Zn} \mathrm{K}$ edge $(1.28324 \AA)$ in the interval 1.18-1.3 $\AA$ in steps of $0.0001 \AA$. Data processing was performed in Athena. ${ }^{63}$ The background was subtracted using a first order polynomial to model the pre-edge region. Normalization of the data was performed in order to account for small deviations in packing densities and enabling qualitatively comparison of the data. The EXAFS signal was extracted from the absorption spectrum by subtracting the modelled absorption from a chemically isolated $\mathrm{Zn}$ atom. This was estimated by fitting cubic splines as a smooth background to the absorption spectrum in the range $0-1.17 \AA$. The range $3.0-9.7 \mathrm{eV}$ of the EXAFS signal was weighted by a Hanning function and Fourier transformed to obtain a radial distribution function in real space. The first four coordination shells (1.35-4.0 Å) were back Fourier transformed, weighted by a Hanning function. The resulting spectra were modeled in $k$-space in Artemis. ${ }^{63} \mathrm{ZnO}$ and $\mathrm{Zn}\left(\mathrm{NO}_{3}\right)_{2}$ were used as references to refine the many-body reduction factor, $S_{0}$, which was then fixed for the remaining samples, Sref. The path distances were fitted for all included shells based on calculations of theoretical scattering paths in the program $f_{\text {eff. }}$ There was assumed no shift in the threshold energy $E_{0}$ and the coordination number were fixed according to full occupancy on the sites to avoid over parametrization. 
Inversion of the cations was constructed for the first shell by generating two paths with either Zn tetrahedrally coordinated (direct spinel) or octahedrally coordinated (inverse spinel). For these paths $\mathrm{N}$ was fixed to 1 and $S_{0}$ defined by $S_{0}(8 a)=S_{r e f} \cdot 4 \cdot(1-i)$ for $\quad 0>i>1, \quad$ and $S_{0}(16 d)=S_{\text {ref }} \cdot 6 \cdot i$

\section{${ }^{27} \mathrm{Al}$ NMR}

The solid-state ${ }^{27}$ Al MAS NMR spectra were acquired on a Varian Direct-Drive VNMRS-600 (14.09 T) spectrometer using a home-built CP/MAS NMR probe for $4 \mathrm{~mm}$ o.d. rotors and a spinning frequency of $\nu_{R}=13.0 \mathrm{kHz}$. Quantitatively reliable spectra were obtained by a $0.5 \mu \mathrm{s}$ excitation pulse for an $\mathrm{rf}$ field strength of $\gamma B_{1} / 2 \pi=60 \mathrm{kHz}$ (i.e. a flip angle $<30^{\circ}$ ), a 2-s relaxation delay and +2000 scans. The spectra shown in the SI are referenced to a $1.0 \mathrm{M}$ aqueous solution of $\mathrm{AlCl}_{3} \cdot 6 \mathrm{H}_{2} \mathrm{O}$.

\section{Physical Property Characterization}

Diffuse Reflectance Ultraviolet Spectroscopy measurements were conducted on a Shimadzu UV3101 PC spectrometer. The operating interval was $200-2500 \mathrm{~nm}$ and the measurements were performed at room temperature. The acquired reflectance was converted to absorbance through the Kubelka Munk function, $\frac{C}{S}=(1-R)^{2}(2 R)^{x}$. C the absorbance, $\mathrm{R}$ is the reflectivity and $\mathrm{S}$ the scattering coefficient. For $\mathrm{ZnAl}_{2} \mathrm{O}_{4}$ there is a direct transition at the $\Gamma$ point, ${ }^{27,28}$ as a consequence $x=1 / 2$. The band gap was extracted from the straight part of the Kubelka Munk function.

\section{CONCLUSION}


We have inspected a range of spinel $\mathrm{ZnAl}_{2} \mathrm{O}_{4}$ samples synthesized using a variation of synthesis techniques. The crystal structures of the samples were characterized by SPXRD, PDF, NMR and EXAFS in order to understand the nature of the structural defects and correlate these to observed absorption spectra. The extracted degree of inversion from PDF, Zn-EXAFS and SPXRD analysis was incompatible with values from ${ }^{27} \mathrm{Al}$ NMR data. For the highly defect M2w sample, SPXRD and PDF analysis suggested a three times lower inversion degree than ${ }^{27} \mathrm{Al}$ NMR $(0.3$ vs 0.1$)$. Since ${ }^{27} \mathrm{Al}$ NMR has no inherent model bias, it is likely the most reliable technique to determine the ratio of tetrahedral to octahedral $\mathrm{Al}$ assuming a fully crystalline sample. However, the NMR data do not give information about the specific crystal structure and thus the ratio of tetrahedral to octahedral aluminum must be put into context by analysis based on scattering data.

MEM analysis of SPXRD data showed residual electron density at the two interstitial sites $16 c$ and $48 f$, which based on valence calculations most likely is due to occupation by $\mathrm{Zn}$ ions. Including occupancy refinement on these interstitial sites still resulted in large discrepancy between the PDF/SPXRD and ${ }^{27} \mathrm{Al}$ NMR with regard to the estimated degree of cation inversion. The interstitial model was too complex for analysis of the Zn-EXAFS data (over-parametrization).

The present SPXRD and PDF refinements did not consider oxygen vacancies, which on the other hand are the most feasible explanation to the defect states in the absorption spectra. The degree of cation inversion correlates strongly with the oxygen occupancy, and independent refinement is not possible.

It appears that the Zn-EXAFS, PDF and SPXRD techniques are not able to independently give reliable estimates of the cation inversion in this $\mathrm{ZnAl}_{2} \mathrm{O}_{4}$ spinel structure. This is despite the data being of highest quality and $\mathrm{Zn}$ having four times the scattering power of Al. The most reliable structural model based on the multiple technique data constrain the degree of inversion to the ${ }^{27} \mathrm{Al}$ 
NMR values while refining the occupancy on the $16 c$ and $48 f$ site (Model 10). This model estimates that for the M2w sample the amount of interstitial defects is similar to the degree of cation inversion. Interstitial cations implicitly give a charged crystal, and thus in reality the crystal structure must also have cation deficiency on the main sites. Such cation deficiency (superimposed on the inversion) was not modelled here.

The concentration of both the inversion and the interstitial defects can be strongly manipulated through the choice of synthesis method. Furthermore, it appears that a significant amount of oxygen vacancies are present, which significantly affect the absorption spectra. The oxygen vacancies can be can be tuned by heat treatment. The more defective samples show highly complex absorption curves, which is promising when considering $\mathrm{ZnAl}_{2} \mathrm{O}_{4}$ as a phosphor, whereas the defect free samples can be used as white host compounds.

\section{ACKNOWLEDGEMENTS}

This work was supported by the Villum Foundation and the Danish Center for Synchrotron and Neutron Research (Danscatt). The synchrotron radiation experiments were performed at BL26B2 and BL44B2 in SPring-8 with the approval of RIKEN (Proposal No. 20160037) and P02.1, DESY, PETRA III, Deutsches Elektronen-Synchrotron, DESY, a member of the Helmholtz Association (HGF). N. L. would like to acknowledge the VILLUM foundation (VKR 023449) for financial support. Hazel Reardon is thanked for fruitful discussions.

\section{CORRESPONDING AUTHOR}

Bo Brummerstedt Iversen, bo@,chem.au.dk 
Center for Materials Crystallography, Department of Chemistry and Interdisciplinary Nanoscience Center (iNANO), Aarhus University, Langelandsgade 140, 8000-DK Aarhus, Denmark

\section{PRESENT ADDRESS}

a Center for Materials Crystallography, Department of Chemistry and Interdisciplinary Nanoscience Center (iNANO), Aarhus University, Langelandsgade 140, 8000-DK Aarhus, Denmark

b Interdisciplinary Nanoscience Center (iNANO), Aarhus University, Gustav Wieds vej 14, 8000DK Aarhus, Denmark

${ }^{\mathrm{c}}$ Department of Engineering and iNANO, Aarhus University, DK-8000 Aarhus, Denmark

${ }^{d}$ Faculty of Pure and Applied Sciences, 1-1-1 Tennodai, Tsukuba, Ibaraki 305-8571, University of Tsukuba, Japan

${ }^{\mathrm{e}}$ Department of Chemistry and iNANO, Aarhus University, DK-8000 Aarhus, Denmark

\section{REFERENCES}

1. F. H. S. Vermaas and E. R. Schmidt, Contrib. Mineral. Petrol., 1959, 6, 219-232.

2. M. Lenglet and F. Hochu, Mater. Res. Bull., 1997, 32, 863-872.

3. H. A. Bethe, Ann. Physik, 1929, 3, 133.

4. J. H. Van Vleck, Phys. Rev., 1932, 41, 208-215.

5. N. Basavaraju, K. R. Priolkar, D. Gourier, S. K. Sharma, A. Bessière and B. Viana, Phys. Chem. Chem. Phys., 2015, 17, 1790-1799.

6. M. Fabián, P. Bottke, V. Girman, A. Düvel, K. L. Da Silva, M. Wilkening, H. Hahn, P. Heitjans and V. Šepelák, RSC Adv., 2015, 5, 54321-54328. 
7. L. Cornu, M. Gaudon and V. Jubera, J. Mater. Chem. C, 2013, 1, 5419-5428.

8. S. Mathur, M. Veith, M. Haas, H. Shen, N. Lecerf, V. Huch, S. Hüfner, R. Haberkorn, H. P. Beck and M. Jilavi, J. Am. Ceram. Soc., 2001, 84, 1921-1928.

9. T. Tangcharoen, W. Klysubun and C. Kongmark, J. Mol. Struct., 2019, 1182, 219-229.

10. R. D. Shannon, Acta Crystallogr. A, 1976, 32, 751-767.

11. H. S. C. O'Neill and W. Dollase, Phys. Chem. Miner., 1994, 20, 541-555.

12. T. F. Barth and E. Posnjak, Z. Krist. Cryst. Mater., 1932, 82, 325-341.

13. H. Spiridigliozzi, A. Pille, F. Schoenstein, L. Museur, E. Feldbach, H. Mändar, M. Kitaura and A. Kanaev, J. Eur. Ceram. Soc., 2020, 40, 3215-3221.

14. S. A. Mirbagheri, S. M. Masoudpanah and S. Alamolhoda, Optik, 2020, 204, 164170.

15. H. Dixit, N. Tandon, S. Cottenier, R. Saniz, D. Lamoen and B. Partoens, Phys. Rev. B, 2013, 87, 174101.

16. J. A. Ball, S. T. Murphy, R. W. Grimes, D. Bacorisen, R. Smith, B. P. Uberuaga and K. E. Sickafus, Solid State Sci., 2008, 10, 717-724.

17. L. Aldon, P. Kubiak, M. Womes, J. C. Jumas, J. Olivier-Fourcade, J. L. Tirado, J. I. Corredor and C. Pérez Vicente, Chem. Mater., 2004, 16, 5721-5725.

18. E. Tronc, J. P. Jolivet and R. Massart, Mater. Res. Bull., 1982, 17, 1365-1369.

19. Y. Xia, T. Wang, X. Zhao, X. Jiao and D. Chen, J. Phys. Chem. B, 2018, 122, 5509-5517.

20. M. A. Lahmer, Surf. Sci., 2019, 682, 75-83.

21. N. Pathak, P. S. Ghosh, S. Saxena, D. Dutta, A. K. Yadav, D. Bhattacharyya, S. N. Jha and R. M. Kadam, Inorg. Chem., 2018, 57, 3963-3982.

22. D. Carta, M. F. Casula, A. Falqui, D. Loche, G. Mountjoy, C. Sangregorio and A. Corrias, J. Phys. Chem. C, 2009, 113, 8606-8615. 
23. D. Carta, G. Mountjoy, G. Navarra, M. F. Casula, D. Loche, S. Marras and A. Corrias, J. Phys. Chem. C, 2007, 111, 6308-6317.

24. S.-F. Wang, G.-Z. Sun, L.-M. Fang, L. Lei, X. Xiang and X.-T. Zu, Sci. Rep., 2015, 5, 12849.

25. N. Van der Laag, M. Snel, P. Magusin and G. De With, J. Eur. Ceram. Soc., 2004, 24, $2417-2424$.

26. M. Han, Z. Wang, Y. Xu, R. Wu, S. Jiao, Y. Chen and S. Feng, Mater. Chem. Phys., 2018, 215, 251-258.

27. H. Dixit, N. Tandon, S. Cottenier, R. Saniz, D. Lamoen, B. Partoens, V. V. Speybroeck and M. Waroquier, New J. Phys, 2011, 13, 063002.

28. F. Zerarga, A. Bouhemadou, R. Khenata and S. Bin-Omran, Solid State Sci., 2011, 13, $1638-1648$.

29. X. Y. Chen, C. Ma, Z. J. Zhang and B. N. Wang, Mater. Sci. Eng., B, 2008, 151, 224-230.

30. S. K. Sampath and J. F. Cordaro, J. Am. Ceram. Soc., 1998, 81, 649-654.

31. N. Pathak, S. K. Gupta, K. Sanyal, M. Kumar, R. M. Kadam and V. Natarajan, Dalton Trans., 2014, 43, 9313-9323.

32. M. E. Foley, R. W. Meulenberg, J. R. McBride and G. F. Strouse, Chem. Mater., 2015, 27, 8362-8374.

33. N. Basavaraju, K. R. Priolkar, D. Gourier, S. K. Sharma, A. Bessière and B. Viana, Phys. Chem. Chem. Phys.,, 2015, 17, 1790-1799.

34. R. G. Dhere, M. Bonnet-Eymard, E. Charlet, E. Peter, J. N. Duenow, J. V. Li, D. Kuciauskas and T. A. Gessert, Thin Solid Films, 2011, 519, 7142-7145. 
35. S. Sommer, E. D. Bøjesen, A. B. Blichfeld and B. B. Iversen, J. Solid State Chem., 2017, 256, 45-52.

36. S. Sommer, E. D. Bøjesen, H. Reardon and B. B. Iversen, Cryst. Growth Des., 2020, 20, 3, 1789-1799.

37. B. Rees, Acta Crystallogr. A, 1976, 32, 483-488.

38. M. Stokkebro Schmøkel, L. Bjerg, J. Overgaard, F. Krebs Larsen, G. K. Hellerup Madsen, K. Sugimoto, M. Takata and B. Brummerstedt Iversen, Angew. Chem. Int. Ed., 2013, 52, 1503-1506.

39. H. Yin, A. B. Blichfeld, M. Christensen and B. B. Iversen, Appl. Mater. Interfaces, 2014, 6, 10542-10548.

40. A. Della Giusta, F. Princivalle and S. Carbonin, Mineral Petrol., 1987, 37, 315-321.

41. C. M. Zeuthen, P. S. Thorup, N. Roth and B. B. Iversen, J. Am. Chem. Soc., 2019, 141, 8146-8157.

42. P. Jones, Chem. Soc. Rev., 1984, 13, 157-172.

43. B. B. Iversen, F. K. Larsen, M. Souhassou and M. Takata, Acta Crystallogr. B, 1995, 51, $580-591$.

44. D. M. Collins, Nature, 1982, 298, 49.

45. F. Cargnoni, E. Nishibori, P. Rabiller, L. Bertini, G. J. Snyder, M. Christensen, C. Gatti and B. B. Iversen, Chem.: Eur. J., 2004, 10, 3861-3870.

46. M. Takata, B. Umeda, E. Nishibori, M. Sakata, Y. Saitot, M. Ohno and H. Shinohara, Nature, 1995, 377, 46-49.

47. I. Brown and D. Altermatt, Acta Crystallogr. B, 1985, 41, 244-247.

48. Z. Chen, E. Shi, Y. Zheng, W. Li, N. Wu and W. Zhong, Mater. Lett., 2002, 56, 601-605. 
49. S. G. Menon, K. S. Choudhari, S. A. Shivashankar, S. Chidangil and S. D. Kulkarni, New J. Chem., 2017, 41, 5420-5428.

50. R. F. Cooley and J. S. Reed, J. Am. Ceram. Soc., 1972, 55, 395-398.

51. S. Mathur, M. Veith, M. Haas, H. Shen, N. Lecerf, V. Huch, S. Hüfner, R. Haberkorn, H. P. Beck and M. Jilavi, J. Am. Ceram. Soc., 2001, 84, 1921-1928.

52. V. Šepelák, L. Wilde, U. Steinike and K. D. Becker, Mater. Sci. Eng., A, 2004, 375-377, $865-868$.

53. P. Shukla, A. Chernatynskiy, J. C. Nino, S. B. Sinnott and S. R. Phillpot, J. Mater. Sci., 2011, 46, 55-62.

54. J. Song, D. W. Shin, Y. Lu, C. D. Amos, A. Manthiram and J. B. Goodenough, Chem. Mater., 2012, 24, 3101-3109.

55. Y. Seminovski, P. Palacios, P. Wahnón and R. Grau-Crespo, Appl. Phys. Lett., 2012, 100, 102112.

56. K. Kato, R. Hirose, M. Takemoto, S. Ha, J. Kim, M. Higuchi, R. Matsuda, S. Kitagawa and M. Takata, 2010.

57. L. Lutterotti, Acta Crystallogr., Sect. A: Found. Crystallogr, 2000, 56, S54.

58. H. Tanaka, M. Takata, E. Nishibori, K. Kato, T. Iishi and M. Sakata, J. Appl. Crystallogr., 2002, 35, 282-286.

59. A. Hammersley, S. Svensson, M. Hanfland, A. Fitch and D. Hausermann, Int. J. High Pressure Res., 1996, 14, 235-248.

60. P. Juhas, T. Davis, C. L. Farrow and S. J. L. Billinge, J. Appl. Crystallogr., 2013, 46, 560566. 
61. F. de la Pena, T. Ostasevicius, V. Tonaas Fauske, P. Burdet, P. Jokubauskas, M. Nord, M. Sarahan, E. Prestat, D. N. Johnstone, J. Taillon, u. Jan Caron, T. Furnival, K. E. MacArthur, A. Eljarrat, S. Mazzucco, V. Migunov, T. Aarholt, M. Walls, F. Winkler, G. Donval, B. Martineau, A. Garmannslund, L.-F. Zagonel and I. Iyengar, Microsc. Microanal, 2017, 23, 214-215.

62. G. Ueno, H. Kanda, R. Hirose, K. Ida, T. Kumasaka and M. Yamamoto, J. Struct. Funct. Genomics, 2006, 7, 15-22.

63. B. Ravel and M. Newville, J. Sync. Rad., 2005, 12, 537-541. 